Forthcoming in Philosophical Studies

\title{
Pretense, Imagination, and Belief: the Single Attitude Theory
}

\author{
Peter Langland-Hassan
}

\begin{abstract}
A popular view has it that the mental representations underlying human pretense are not beliefs, but are "belief-like" in important ways. This view typically posits a distinctive cognitive attitude (a "DCA") called "imagination" that is taken toward the propositions entertained during pretense, along with correspondingly distinct elements of cognitive architecture. This paper argues that the characteristics of pretense motivating such views of imagination can be explained without positing a DCA, or other cognitive architectural features beyond those regulating normal belief and desire. On the present "Single Attitude" account of imagination, propositional imagining just is a form of believing. The Single Attitude account is also distinguished from "metarepresentational" accounts of pretense, which hold that both pretending and recognizing pretense in others require one to have concepts of mental states. It is argued, to the contrary, that pretending and recognizing pretense require neither a DCA nor possession of mental state concepts.
\end{abstract}

\section{Introduction}

Before the age of three, children recognize and spontaneously engage in a wide variety of pretenses (P. Harris and Kavanaugh 1993). The phenomenon is fascinating on its face: one would expect that keeping track of two worlds simultaneously - the real and the pretendedrequires a level of cognitive sophistication not achieved until much later. After all, it is only between four and five that children begin to reliably pass standard false-belief tasks, showing a clear understanding of the distinction between how things are and how they are mentally represented (Wellman et al. 2001). ${ }^{1}$ At the same time, pretense offers a valuable avenue of approach towards the otherwise quite slippery phenomenon of imagination. For if we assume

\footnotetext{
${ }^{1}$ In a standard false belief task, the subject watches an experimenter (or a puppet) place an object in a container. The experimenter then leaves the room and an accomplice takes the object out of the container and places it in another container nearby. The subject is then asked where the experimenter will look for the object when she returns. Subjects who indicate that the experimenter will look in the container where the object was first placed are taken to understand (at least implicitly) that the experimenter has a false belief about the location of the object. That said, failure of standard false belief tasks should not be taken as proof positive of a lack of mental state understanding, as other factors may account for the failures (Bloom and German 2000). Moreover, some have recently cited results from looking-time and "active helping" paradigms to argue that children as young as 15 months have some understanding of mental states (Onishi and Baillargeon 2005; Buttlemann et al. 2009). Thus, the matter of precisely which concepts-mental and otherwise-young children possess remains controversial.
} 
that one's behavior during a pretense is driven in large part by what one is imagining - that imagining is the cognitive component of pretending — then in explaining the cognition underlying and enabling pretense one is simultaneously providing an account of a central form of imagination. This means that there is a way of theorizing about imagination that does not reduce to asking people what they introspectively take themselves to be up to when they imagine. Understanding imagination becomes a matter of understanding child's play.

Motivated in large part by its ability to explain pretense, a view has taken hold in recent years according to which propositional imagining - imagining that thus and such-involves a distinctive cognitive "attitude." The core idea is that, just as belief and desire constitute two different attitudes one can take toward a proposition, so too is there an "imaginative" attitude that one can take toward a proposition, accounting for thoughts that are functionally quite different from any beliefs or desires one might entertain. Note that the claim that there is a cognitive attitude of imagination is considerably stronger than the mere truism that people imagine that thus and such; those who advance the view intend it as an empirically testable hypothesis about the cognitive architecture that underlies the ability to imagine that thus and such (see, e.g. Nichols \& Stich (2000, p. 117), Weinberg \& Meskin (2006a, 2006b), and Schroeder \& Matheson (2006)).

Nichols and Stich (2000; 2003 Ch. 2) develop one of the most influential accounts of this cognitive attitude as a way of explaining a range of phenomena surrounding human pretense. Their theory seeks to formalize two common claims about propositional imagining. The first is that it does indeed involve a cognitive attitude distinct from both belief and desire; the second is that this attitude bears important functional similarities to belief. Packaged together, these two ideas form the foundation of the "DCA account" or "DCA hypothesis" concerning imagination —where 'DCA' stands for 'distinct cognitive attitude.'

While there have been many proposed amendments and buttresses to Nichols and Stich's development of the DCA hypothesis, ${ }^{2}$ the view's central claim that propositional imagining involves a distinct, belief-like cognitive attitude (realized in correspondingly distinct elements of cognitive architecture) is widely accepted (Carruthers 2006; Currie and Ravenscroft 2002, Ch. 2; Friedman and Leslie 2007; Gendler 2006; Schroeder and Matheson 2006; Weinberg and Meskin 2006b). Noting this "remarkable convergence of opinion," Schroeder and Matheson offer their 2006 as "a final seal of approval" (p. 19) upon the idea that pretense involves the activity of a

\footnotetext{
${ }^{2}$ For friendly amendments to N\&S's account, see Carruthers (2006), Currie \& Ravenscoft (2002), Doggett \&Egan (2007), Gendler (2003), and Weinberg \& Meskin (2006a).
} 
distinct belief-like cognitive attitude, while Nichols remarks that the DCA hypothesis is "embraced by most contemporary cognitivist accounts of pretense and imagination" and is "perhaps, the most productive idea about the propositional imagination that anyone has ever had" (2004, 2006b).

This paper diverges from the convergence. I will argue that theorists have been too quick to dismiss a simpler alternative-namely, that pretense requires only ordinary belief and desire. The characteristics of pretense that Nichols and Stich, and many others, take to strongly support the DCA hypothesis can all be explained without the introduction of a DCA, and without attributing to pretenders any beliefs or desires over and above those that proponents of the DCA hypothesis must also attribute as part of their own accounts. Thus, not only is the view I will defend more parsimonious in the sense that it makes fewer posits, it makes do with a subset of the mechanisms and processes posited by DCA views. This means that DCA theorists cannot allow that the present view adequately captures the phenomena in question without thereby admitting that their own account makes explanatorily redundant posits. ${ }^{3}$

While the human capacity for pretense creates probably the clearest case in favor of the DCA hypothesis, DCA theorists have adduced other phenomena in favor of the theory as well. These include, most notably, the phenomenon of affective response to merely imagined and pretended scenarios, and the co-presence of mindreading and pretense deficits in children with autism (see, e.g., Nichols 2004; Currie and Ravenscroft 2002, Ch. 7-8; Weinberg and Meskin 2006a). Assessing such claims requires carefully interpreting results from a variety of empirical literatures; I will not have space to do so here. In this paper I will focus exclusively on the phenomenon of pretense, arguing that with respect to explaining pretense, a simpler and more powerful cognitive account is available that does not posit a DCA. ${ }^{4}$

My view, in a nutshell, is that imagining that $p$ amounts to making judgments about what would likely happen if $p$, from retrieved beliefs in relevant generalizations; and, pretending that $p$ is using such judgments to act in ways that would be appropriate if $p$ (both of these characterizations are sharpened below). None of this, I argue, requires positing a cognitive attitude distinct from belief; call it a single attitude account of pretense and imagination (though

\footnotetext{
${ }^{3}$ Of course, it is possible that human cognitive architecture is redundant in various ways, and that specific patterns of dissociation might weigh in favor of the very redundancy to which DCA views are (I will argue) committed. I will not have space to discuss evidence deriving from dissociations here. My more modest goal is to articulate an overlooked yet simpler cognitive explanation of the phenomena surrounding pretense. With the view in place, we can then turn to the empirical literature to see whether there is nevertheless support for a redundant architecture of the kind posited by DCA views.

${ }^{4}$ It is worth emphasizing, however, that N\&S cite pretense as providing the initial motivation for their view (2003).
} 
some desire is needed, too). ${ }^{5}$ To be clear, I do not deny that people propositionally imagine. I simply maintain that, at the level of cognitive architecture, propositional imagining requires only beliefs and desires. ${ }^{6}$

The next section lays out the characteristics of pretense that Nichols and Stich (hereafter, "N\&S") correctly argue a cognitive theory of pretense should help explain, and Section Three looks in detail at N\&S's explanation of these features. Section Four then develops a simpler Single Attitude (hereafter "SA") alternative that, if viable, shows N\&S's core posit—the "Possible Worlds Box"— to be explanatorily redundant. Section Five moves on to distinguish the SA approach from another influential theory of pretense, the "metarepresentational" view of Leslie (1987, 1994), and Friedman \& Leslie (2007). There I respond to criticisms Friedman \& Leslie (2007) levy against N\&S's “behavioral” account of pretense recognition which, if cogent, would apply to the SA view as well. I argue that, contrary to their claims, that the pretense recognition capacities of young children do not require us to ascribe to them mental state concepts. I conclude that pretending and imagining can be explained without appeal to a DCA and without attributing to pretenders an understanding of mental states.

\section{Child's play: what a theory of pretense needs to explain}

A commonly cited example in discussions of pretense, including that of N\&S, comes from Leslie (1994), who reports on an experiment where children have a pretend tea party. It can be used to bring out the key features of pretense that a theory should help explain. Here is the passage from Leslie cited by N\&S:

The child is encouraged to "fill" two toy cups with "juice" or "tea" or whatever the child designated the pretend contents of the bottle to be. The experimenter then says, "Watch this!", picks up one of the cups, turns it upside down, shakes it for a second, then replaces it alongside the other cup. The child is then asked to point at the "full cup" and at the

\footnotetext{
${ }^{5}$ I will not offer any particular account of belief. The standard, if unilluminating, characterizations will have to do: to believe something is to take it to be the case, or to accept it as true; beliefs are functionally distinguished by their privileged role in guiding action and practical reasoning. I intend these not as philosophically adequate characterizations of belief, but as an indication that I am not working with any special or controversial conception of belief.

${ }^{6}$ Just as I will not have space here to canvass all the considerations raised in favor of DCA views, neither can I hope to fully explain or defend an account of propositional imagination. I hope only to establish here that pretense does not by itself provide reason to think that propositional imagining requires a DCA.
} 
“empty cup" (both cups are, of course, really empty throughout)" (Leslie 1994, quoted in Nichols and Stich, 2000, p. 117).

\subsection{Quarantining}

Ten out of ten two-year-olds in Leslie's experiment identified the cup that had been turned upside down as the "empty cup," and the one that had not been overturned as the "full cup." One of the central questions motivating pretense research since Leslie's seminal 1987 concerns the issue of cognitive "quarantine": how do children (and adults, for that matter) manage to keep what they believe separate from what they are merely pretending? How does the child, who really believes both cups to be empty, keep track of the fact that one of the cups is "full" in the pretense, without falling into a kind of representational "chaos" or "abuse" (Leslie 1987), whereby the cup is simultaneously represented as both full and empty? What sort of cognitive mechanisms and representations make this possible?

A related phenomenon this example reveals is that one can pretend (or imagine) that $p$ while believing that not $p$ (the child pretends that a cup is full, while believing it not to be full); and one can also pretend (or imagine) that $p$ while believing that $p$ (the child both pretends that the overturned cup is empty and believes it to be empty). Any cognitive theory of pretense must explain how this can be so. This feature of imagination will be grouped together with the question of how pretenders keep separate what is pretense from what is real under the rubric of quarantining.

\subsection{Inference}

Another important group of features in pretense can be placed under the rubric of inference. Nichols and Stich note that when pretenders elaborate the details of a pretense, they very often do so through a series of inferences that mirrors closely the beliefs that would be formed were the pretense real. Nichols (2006a) calls this phenomenon "inferential orderliness." In the tea party example, when one of the cups is overturned, the children infer that it has become "empty," just as they would have come to believe it was empty had it actually been filled and then overturned (or if they had simply learned through testimony that a full cup was overturned). Currie and Ravenscroft highlight the same phenomenon, suggesting that the attitude underlying propositional imagination is "belief-like" in that it "preserves the inferential patters of belief" (2002, p. 12). 
This phenomenon can be grouped in combination with what N\&S separately identify as the ability of pretenders to engage in behavior "appropriate" to the pretense (2000, pp. 119-120). Those engaging in pretense not only make inferences that mirror the beliefs they would form were the pretense real, they also-within certain limits-behave in a way that mirrors the way they would behave were the pretense real. A person pretending that a banana is a telephone will often speak into one end of the banana and put the other end to her ear, just as she would if the banana were actually a telephone.

Nevertheless, as N\&S also stress, such "inferential orderliness" is only a norm; in many cases things are inferred in an act of pretense that one would not normally come to believe or act out in reality. When told to imagine that Bob was in New York yesterday and London today, one will typically imaginatively infer that he traveled to London by plane (as one would likely come to believe were one simply told this information). But there may also be cases where, for whatever reason, one fills out the scenario by imagining that Bob made the journey via teleportation, or by flapping his arms. So, there is latitude in imaginative inference-a possibility of divergence from what one would believe were the situation real- that must also be accounted for.

Under the general rubric of inference, then, there are three related questions that a theory of propositional imagination would ideally shed light on: why do the inferential patterns of imagination usually mirror those of belief; how do these inferences connect with and guide a pretender's outward behavior; and, how can imagination and pretense nevertheless sometimes radically diverge from what we would come to believe or do were the pretend situation real?

\subsection{Conceptual nä̈veté}

A last important aspect of pretense highlighted by the tea party example is that the ability to engage in pretense develops early in childhood. By two years of age children frequently and spontaneously engage in group and solitary pretend play (Bosco et al. 2006; Leslie 1987; Onishi et al. 2007). However, children of this age do not reliably pass standard false belief tasks (Wellman et al. 2001). Moreover, even at the age of four most children have difficulty understanding the relation between what is pretended and the pretender's intentions and beliefs (Lillard 1993; Sobel and Lillard 2002). ${ }^{7}$ This suggests that one need not have mastered

\footnotetext{
${ }^{7}$ In Lillard's (1993) influential study, four-year-olds were shown a toy troll named 'Moe,' who hopped up and down. The children were told that Moe was from the land of trolls where there are no kangaroos, and that he did not know what kangaroos are. Asked if Moe was pretending to be a kangaroo, most subjects replied that he was. Thus,
} 
sophisticated psychological concepts, or be able to process complex inference patterns, in order to pretend. Whatever concepts and inferential abilities pretense requires should be ones we can plausibly attribute to two-year-olds.

\section{Nichols and Stich's Possible Worlds Box}

Nichols and Stich's project is to shed light on as many of these features of pretense as possible, while working within the basic framework of "cognitivist" or "representationalist" propositional attitude psychology. They note two key assumptions (both accepted here) of this common framework. The first is that there are (at least) two very different kinds of mental states-beliefs and desires - that are distinguished functionally, in terms of their distinctive patterns of interaction with other mental states and cognitive mechanisms. It is customary in diagrams that map out cognitive architecture to assign a "box" for each type of state-e.g., the Belief Box and the Desire Box. The "boxes" signify that the representations grouped there bear important functional (and not necessarily neurobiological) similarities. Depending on the details of one's theory of cognitive architecture, these "boxes" have a range of connections with other mechanisms, and with inputs and outputs to the cognitive system.

The second assumption is that beliefs and desires, and whatever other propositional attitudes there may be, involve a relation between an "attitude" and a content. Thus, in describing a thought, we can distinguish between the attitude (e.g., of belief or desire) taken toward a content, and the content itself. Two thoughts can then differ in terms of attitude, content, or both (e.g., the belief that it is raining shares content with but differs in attitude from the desire that it is raining). Moreover, it is perfectly coherent to believe that $p$ while desiring that not- $p$; where there are distinct attitudes, conflicting contents are typically unproblematic. But it is generally considered irrational to believe that $\mathrm{p}$ and not-p, or desire that $\mathrm{p}$ and not-p.

Nichols and Stich's central claim, shared in one form or another by all DCA theorists, is that imagining is a propositional attitude in addition to belief and desire-one which warrants its very own "box" within diagrams of cognitive architecture (they call it the "Possible Worlds Box" (PWB); Nichols (2004) later dubs it the "Pretense Box"). They argue that positing the PWB provides the best means for explaining the various facts about pretense described above.

despite successfully passing a standard false belief task, most of the children seemed to have a conception of pretense according to which pretending to be something amounts to acting like that thing, regardless of one's intentions, beliefs, or other representational mental states. 
Let us use 'imagination' for the attitude taken toward a proposition in virtue of its being in one's PWB (though 'supposition' might work equally well; there is no requirement on their view that mental imagery is involved in —or absent from-imagination). We can understand the relation between imagination and pretense to be roughly as follows: pretense always involves some outward behavior that is partly driven by what the pretender imagines. One can, of course, simply imagine various things without engaging in outward pretend behavior; the point is that when one does engage in pretend behavior, it is guided by what one is imagining. Theories of propositional imagination, then, specify what goes on mentally during a pretense, with the proviso that not all cases of imagining are cases of pretending.

Looking first at the issue of quarantining, $N \& S$ suggest that the PWB accounts for the cognitive system's ability to keep propositions relevant to one's imaginative project separate from those towards which one has the attitude of belief or desire. Of course, the Possible Worlds "Box" is simply shorthand for a range of functional similarities possessed by certain representations in the mind; so, these functional similarities in the way the representations are processed (and their contrast with the functional characteristics of beliefs) explain how confusion is avoided and accurate reports are given concerning what is believed versus what is imagined.

Moreover, the existence of a distinctive imaginative attitude helps explain how one can believe that $p$ while imagining (or pretending) that not $p$, or imagine (or pretend) that $p$ while believing that $p$. For, provided that imagining is, like desire, its own cognitive attitude, there is no obvious epistemic difficulty—no threat of "inferential chaos" - presented by the fact that one imagines that $p$ while believing that not- $p$, just as there are no such problems inherent in believing that $p$ while desiring that not $-p$.

Turning to the issues grouped under the rubric of inference, $N \& S$ hold that it is in the PWB that the inferences and elaborations relevant to guiding a pretense take place. The tea party pretense begins "when a representation with the content We are going to have a tea party is placed in the PWB" (p. 122). What happens next is:

The cognitive system starts to fill the PWB with an increasingly detailed description of what the world would be like if the initiating pretense were true... in Leslie's tea party scenario, at the point in the pretense where Alan has just turned the green cup upside down has been added to the PWB, the child's cognitive system has to arrange to get The green cup is empty in there too (p. 122). 
This new representation will arrive via a process of inference that goes on in the PWB. N\&S posit that such inferences occur through the work of the same "inference mechanism" that guides the formation and revision of beliefs, and that this mechanism is able to work on representations in both boxes precisely because they are "in the same code" (pp. 122-125). ${ }^{8}$

Yet, they are quick to point out, the inference process will not get very far if the only representation in the PWB is the one that initiates the pretense. After all, there are only so many things that can be inferred from the solitary proposition: we are going to have a tea party. Some further commitments concerning what typically goes on at tea parties are needed for the pretense to develop. N\&S suggest that this extra information has an obvious source: the Belief Box. Along with the pretense-initiating premise, then, "the cognitive system puts the entire contents of the Belief Box into the Possible World Box" (p. 123). This way, a rich set of inferences can be drawn from the pretense-initiating premise. Importantly, it will be a set of inferences that closely mirrors those that would be drawn were one to believe the initial premise, since the very same set of contents serve as additional premises in each case, and the same inference mechanism "works on" representations in each "box".

Of course, some of the beliefs in the Belief Box will likely conflict with the pretend premise (such as, in the above example, the belief that we are not having a tea party), potentially leading to "inferential chaos." N\&S therefore posit an additional cognitive mechanism, the "UpDater," which "goes through the representations in the PWB, eliminating or changing those that are incompatible with the pretense premise" (2000, p. 124). While they admit that it is difficult to understand how the UpDater accomplishes its task, they find it unproblematic to posit such a mechanism because it is needed in any case to explain how belief revision normally occurs.

Concerning the various inferences and behaviors during pretense that do not follow belief-like inference patterns, N\&S admit they “don't have a detailed account of the cognitive mechanisms" that account for them (p. 127). They simply posit an additional component-the "Script Elaborator"- whose job it is to "fill in those details of a premise that can't be inferred from the pretense premise, the (filtered) contents of the Belief Box and the pretender's knowledge of what has happened earlier on in the pretense" (ibid.). As they recognize, positing such a mechanism does little more than provide space for an explanation to come.

\footnotetext{
${ }^{8}$ Nichols and Stich hold that representations are in the same code if they have the same logical form, and their representational properties "are determined in the same way" (2000, p. 125, emphasis in original).
} 
The last issue under the rubric of inference to be discussed is how N\&S connect the activity in the PWB to the actual behavior of pretenders. According to N\&S, "pretenders behave in the way they do because they want to behave in a way that is similar to the way some character or object behaves in the possible world whose description is contained in the Possible World Box" (p. 128, emphasis in original). While this sounds like a rather complex desire to have, they quickly provide a simpler gloss: "To pretend that $\mathrm{p}$ is (at least to a rough first approximation) to behave in a way that is similar to the way one would (or might) behave if $\mathrm{p}$ were the case. Thus, a person who wants to pretend that $\mathrm{p}$ wants to behave more or less as he would if p were the case" (p. 128).

Of course, the desire to behave as one would if $p$ were the case can only be fulfilled if one has some beliefs about how one would behave if $p$ were the case. "The obvious source for this information" they tell us, "is the possible world description unfolding in the PWB" (p. 128). Thus, pretense behavior occurs when the pretender has a desire to behave as she would if $p$, and, by accessing the description "unfolding" in the PWB, is able to form (counterfactual) beliefs about how she would act if $p$ were the case. These beliefs in turn drive the pretense behavior.

We now have a sketch of how N\&S account for the phenomena grouped under the rubrics of 'quarantining' and 'inference.' As for the early emergence of pretense behavior, they believe this fits naturally with their account since "on [their] theory, a pretense could proceed perfectly well even if the subject did not have the concept of pretense" (pp. 137-138). Unlike other views (e.g., Friedman and Leslie 2007; Leslie 1987, 1994) that require pretenders to have intentions of the form, "I pretend that such and such"- - where PRETEND is explicitly a mental state concept- $-\mathrm{N} \& \mathrm{~S}$ suggest that the attitude of imagination can be taken toward a content and thereby enable pretend play, without one's having the concept IMAGINE (or PRETEND), just as one can take the attitude of belief toward a proposition (and so can have a belief) without having the concept BELIEF. Thanks to the DCA of imagination, a child can engage in rich imaginings, using them to guide a pretense, without understanding that she is entertaining mental states of any particular kind.

\section{Imagining in the Belief Box - the Single Attitude Account}

I will now offer a simpler proposal for making sense of the same phenomena, making do with a subset of the mechanisms posited by N\&S. If successful, it weighs strongly against any theory of pretense that appeals to a distinct cognitive attitude. 


\subsection{Imagining that $\mathrm{p}$ without entertaining the proposition that $\mathrm{p}$}

Two key claims of the SA account of pretense are, first, that imagining that $p$ does not require entertaining the proposition that $p$; and, second, one can explain the behavior of pretenders, and the thought processes and cognitive abilities of imaginers, by appeal to beliefs and desires that DCA theorists must also allow pretenders. As we will see, these two claims end up supporting each other.

Entertaining the proposition that $p$, as I will understand it, amounts to being in a representational state with the content $p$, whatever the "attitude" (it does not matter for present purposes whether the state is considered occurrent or merely dispositional). The claim that imagining (and pretending) that $p$ does not require entertaining the proposition that $p$ may strike some as counterintuitive. It is hard to pinpoint the exact reason for this intuitive resistance. Certainly we cannot infer that pretending or imagining that $p$ requires entertaining the proposition that $p$ directly from the fact that there are true statements of the form: ' $\mathrm{X}$ pretended that $p$,' and, 'Y imagined that $p$.' After all, there are plenty of verbs followed by that-clauses that do not transfer to corresponding cognitive "boxes" containing the propositions in question. For instance, Bob can insinuate that the governor is a crook without our needing to posit an "insinuation box," wherein resides the proposition 'the governor is a crook.' Nor does the fact that one can insinuate (or implicate, or simply say) that the governor is a crook while believing that the governor is not a crook, and also while believing that the governor is a crook, obviously stand us in need of a special cognitive quarantine area for the things we insinuate (or say). Bob might insinuate that $p$ while believing that not- $p$ because he wants you to believe that $p$; this involves his having a desire with the content: you believe that $p$. Having that desire does not amount to entertaining the proposition that $p .{ }^{9}$ Why, then, is the situation different for 'imagines'?

One might think that instances of 'imagines that' imply a cognitive attitude because, like 'believes that' and 'desires that', they seems to create intensional (or "referentially opaque") contexts. Intuition (perhaps) has it that someone can imagine that Mark Twain is piloting a steamboat without imagining that Samuel Clemens is piloting a steamboat, just as it is often held that one can believe that Mark Twain piloted steamboats without believing that Samuel Clemens piloted steamboats. But there is an equally plausible alternative explanation for the

\footnotetext{
${ }^{9}$ This is worth emphasizing: having a proposition in the Desire (or Belief) Box that contains $c$ as a proper part is not at all the same thing as having the proposition $c$ in one's Desire (or Belief) Box; if it were, then desiring that not- $c$ would involve desiring that $c$, and believing that not- $c$ would involve believing that $c$.
} 
intensionality of 'imagines that,' which is that propositional imagining reduces to, insofar as it consists in, believing and/or desiring related propositions. If that were right (and I will argue that it is), then instances of ' $X$ imagines that $p$ ' would inherit their intensionality from their relationship to these genuine cognitive attitudes. For now, this possibility is enough to establish that we cannot move directly from the intensionality of 'imagines that' to the conclusion that imagining that $p$ requires entertaining the proposition that $p$, or to the existence of a cognitive "box" containing $p$.

Fortunately, few if any DCA theorists make their case by appeal to such linguistic phenomena. Features of childhood pretense, as evidenced in Leslie's tea party example, are what normally set the views in motion. There were three main facts about the tea party that called for explanation: the phenomenon of "quarantining," the belief-like inferential and behavioral orderliness of the affair (which I grouped under the rubric of 'inference'), and the conceptual naïveté of its participants. Seeing how these can be explained without a DCA requires seeing how the child in Leslie's example can pretend that $p$ without entertaining the proposition that $p$. That is the project I turn to now.

\subsection{What a tea party requires}

For now, let us be agnostic as to whether the children in Leslie's experiment must entertain the proposition that the green cup is empty in order to pretend (and imagine) that the green cup is empty. Begin simply with the uncontested data: the child (correctly) answers the experimenter's question by identifying the cup that was turned over as the one that is "empty," and the one that was not turned over as the one that is "full," while believing all along that both are really empty. What sort of beliefs, desires, and perceptual experiences must the child have to accomplish this?

N\&S correctly note that the child must have a desire to engage in the pretense- - she must "want to behave more or less as [s] we would if $p$ " (where $p$ is 'we are having a tea party'). To act on this desire, she also must have some beliefs about what typically goes on at tea parties. These, too, N\&S allow the child must have; these are the beliefs that, once copied into the PWB, enable inference to "fill out" the PWB description in relevant ways (N\&S call such clusters of beliefs "scripts" or "paradigms" that detail "the way in which certain situations typically unfold" (2000, p. 126)). And, of course, the child must be able to see (or otherwise perceive) what is 
actually going on (is she being handed a cup, watching a kettle tip into a pouring position, being offered a cookie-sized object?).

In addition to these things, N\&S hold that processing in the PWB must occur. Yet the SA theory rejects that claim. To see why, consider the following (PWB-free) suggestion for the thought processes that might occur during such a tea party. We can focus on the crucial step where the child correctly identifies the overturned cup as "empty," and the other as "full," even though both are believed to be empty. P will be used to indicate that a perceptual "attitude" is taken toward the content that follows, B for belief, and D for desire (if one is suspicious of a genuine distinction between perceptual and belief attitudes, a B can be replaced for each $\mathrm{P}$ without affecting the account).

\section{A child's thoughts during a pretend tea-party:}

P1: You say, "Let's have a tea party!" and start setting out dishes and cups. You do all of this with a familiar cluster of mannerisms [e.g., knowing looks and smiles, exaggerated movements and intonation, stopping actions short of normal goal points].

B1: (inferred from P1) You are starting a game where we act in ways that would be appropriate if we were at a tea party, even if we're not at one. ${ }^{10}$

D1: I play this game, too.

P2: You are acting as if ${ }^{11}$ you are pouring tea out of the teapot and into the cups.

B2: (from D1 and P2) I should act as if you poured tea into the cups.

B3: (from B2 and stored generalizations) If you had poured tea into both cups, they would both now be full.

B4: (D1 causes this to be inferred from B3): I should act as if both cups are full.

P3: You put down the bottle and say "watch this!"; you turn the green cup upside down and then put it back on the table, right side up.

B5: (background beliefs): When cups containing liquid are turned upside down, the liquid spills out. When full cups are not moved, they remain full.

\footnotetext{
${ }^{10}$ This is the step where the child effectively recognizes that a pretense is occurring. An obvious question is whether attributing to a child an understanding that a pretense "game" has begun secretly imputes to her an understanding of mental states. I think it does not, but the issues here are complex. I defer further discussion to Section 5.

11 "Acting as if $p$ " should from here forward be understood as equivalent to "acting in ways that would be appropriate if $p$," and not as a mere synonym for "pretending that $p$." More on this in Section 5.
} 
B6: (inferred from P3, B4, and B5): If you had poured tea into both cups and overturned the green one, the green one would now be empty and the other one full.

B7: (inferred from B6, due to D1) I should act like the green cup is empty and the other one is full.

P3: You say, "Show me which cup is empty and which is full."

D1 — an abiding desire to play the game — then leads the child to consult B7 in giving her answer: she points to the green cup to indicate that it is "empty," and then to the other to indicate it is "full."

Note first that none of the beliefs appealed to are "tagged" in any special way to indicate that they are not real beliefs (Cf. Perner, 1991, pp. 53-67). Nor are these beliefs conceptually onerous - they do not involve concepts of mental states. Thus, there is no reason to doubt that two-year olds can engage in a wide variety of such pretenses.

The account does assume the child to have counterfactual beliefs of the form: if $\mathrm{x}$ had been the case, then y would have been,' which there is good reason to think she has. These underlie the "scripts" - the beliefs about how certain types of situations typically go-that N\&S appeal to as well. Indeed, Harris (2001) discusses a variety of empirical studies indicating that "young children [ages 3 to 4] have the competence for counterfactual thinking, spontaneously engage in such thinking, and deploy it in their causal judgments" (p. 252). Of course, N\&S also hold that counterfactual reasoning goes on during pretense - they simply give a different account of the mechanisms by which it occurs.

The most distinctive aspect of the account just provided is that pretending (and imagining) that the green cup is empty does not here involve entertaining the proposition the green cup is empty. Nor does pretending (or imagining) that the other cup is full require entertaining the proposition the other cup is full. Thus, at no time during the pretense does the child entertain a representation with a content that conflicts with—or "duplicates" — that of any of her beliefs. This means there is no proposition in need of quarantining. When the cups are initially "filled" during the pretense, the child does not need to infer (or believe) that the cups are full; rather, she needs to recognize that the experimenter is acting as if ${ }^{12}$ he is pouring tea, and to infer that if tea had been poured in the cups, they would now be full. And she needs to remember, going forward, that as part of the game they are acting as if the cups are full. Such

\footnotetext{
12 "Acting as if" should again be read as "acting in ways that would be appropriate if."
} 
beliefs and inferences pose no threat to any beliefs she has outside of the pretense. So it does not appear that a special process need go on inside a PWB in order for a child to give correct reports about what is going on in the pretense.

To reinforce this point, it may help to consider the matter from the perspective of simple hypothetical reasoning, as the same issues arise there. Indeed, according to N\&S, it is the evolutionary function of the PWB to enable hypothetical reasoning (2003, p. 58). If one wants to know what would happen if $p$ while not believing that $p$ one can, on their view, safely store the proposition $p$ in the $\mathrm{PWB}$, and there carry out the inferences that rationally follow from it, given one's other beliefs (Currie and Ravenscroft (2002, Ch. 2) espouse a similar view).

What N\&S describe is a coherent possibility; nevertheless, hypothetical reasoning does not obviously require a PWB. For example, suppose one wants to hypothetically reason about what will happen if the Cubs win the World Series this year (a hypothetical that promises to remain hypothetical). Call the proposition that the Cubs win the World Series this year ' $c$ '. The desire to know what will happen if $c$ will be enough to cause one to access whatever general beliefs one has about teams that win the World Series. A few likely come to mind: the team jumps for joy ( ' $j$ '), their fans shed tears of elation (' $e$ '), they take part in a ticker-tape parade in their home city (' $t$ '), shirts are printed up (' $s$ '), and so on. Having brought these generalizations to mind, and believing the Cubs to be the sort of thing that falls under those generalizations (i.e., a baseball team), one then infers that if $c$ then probably $j$ and $e$ and $t$ and $s$, etc., and forms the corresponding beliefs. There is no need during all of this to put $c$ itself in either the belief or desire "boxes"- or any "box" at all (hence, no need to "quarantine" c). Turning again to the issue of pretense, if one wishes to pretend that the Cubs have just won the World Series, the inferred (and now believed) conditionals just mentioned will be sufficient to guide a sequence of pretend behavior.

Thus, according to the SA view, there is no need for quarantining during pretense or hypothetical reasoning, as contradictory propositions are not entertained in the first place. Nor is there any peculiarity in a person's ability to imagine or pretend that $\mathrm{p}$ while not believing that $\mathrm{p}$-or indeed while believing that $p$. For the activity of imagining that $\mathrm{p}$ consists merely in retrieving one's beliefs in generalizations relevant to the proposition that $\mathrm{p}$, and using them to make judgments about what would likely happen if $\mathrm{p}$, all of which may (or may not) guide a sequence of pretend behavior. ${ }^{13}$ When they do guide such a sequence of behavior, the person

\footnotetext{
${ }^{13}$ Some may object that this characterization of propositional imagining fails to distinguish it from hypothetical reasoning. In fact, I view propositional imagining as simply one form of (particularly rich) hypothetical reasoning.
} 
moves from merely imagining that $p$ to pretending that $p$. There is no reason to think that one's ability to do any of this would be hampered or confused by a concomitant belief that not- $p$, or that $p$.

As for the pretender's ability to distinguish what is happening in the pretense from what is true outside the pretense, the main difficulty is removed once one gives up the idea that the cognitive system must sort through contradictory propositions (e.g. "the telephone is a banana" and "the telephone is not a banana"), or through multiple copies of the same proposition (e.g. "the cup is empty" (as pretended) and "the cup is empty" (as believed)), in distinguishing the actual from the pretended.

This is obviously not how N\&S envision things. They suggest that, in order to form the beliefs relevant to guiding pretense behavior, one must access the description "unfolding" in the PWB; it is precisely by accessing this information that one comes to have beliefs of the form, "If it were the case that $p$, then it would be the case that $q 1 \& q 2 \ldots \& q \mathrm{n} "$ (p. 128). The assumption apparently driving DCA accounts—N\&S's, and many others-is that, in order to find out what would happen if $p$, one needs to represent (in the PWB, or somewhere else) that $p$ is the case (which is just to represent that $p$ ), and then see what one comes to infer, as opposed to simply accessing whatever beliefs one has about what typically happens in situations where $p$. Harris (2001) explicitly voices this assumption, when he notes that counterfactual reasoning guiding pretense depends "on the ability to temporarily entertain a representation that is non-veridical, and known to be so" (p. 252). ${ }^{14}$ Putting this view in the form of an objection, one might well grant that pretense can sometimes occur in the single-attitude way described-for sometimes, as with the tea party and Cubs cases, we already have beliefs in the needed generalizations-while objecting that this just pushes the question back to how the beliefs in these generalizations are formed. It would seem that a regress threatens, and that the PWB could explain how it is avoided.

But this line of reasoning is mistaken. For representing that $p-$ be it in the PWB, or anywhere else-will result in relevant inferences being made only if one already has beliefs about what is generally true of situations where $p$ (or if one has beliefs about how situations go

But, as noted above, I do not have space here to provide a comprehensive defense of a theory of propositional imagination. I aim only to show that the phenomena surrounding pretense do not require a more expansive account of what it is to propositionally imagine.

${ }^{14}$ Currie \& Ravenscroft share the assumption as well, suggesting that propositional imagining should be seen as enabling a kind of psychological implementation of the Ramsey "test" (2002, p. 12-13). 
when $q$, together with beliefs that allow one to infer that $p$ is a $q$-kind of situation). And if one already has those beliefs, there is no need to represent that $p$ in order to retrieve them; a desire and intention to determine what would happen if $p$ will suffice. If, on the other hand, one has no beliefs about what would likely happen if $p$ (nor any beliefs about how situations go when $q$, together with beliefs that allow one to infer that $p$ is a $q$-kind of situation), nothing will emerge as reasonable when one represents that $p$ in the PWB - for, by hypothesis, there is nothing in the PWB other than $p$ and the copied contents of the Belief Box. So, representing that $p$ in the service of trying to determine what would happen if $p$ is either needless or useless. ${ }^{15}$

This is not to say that the question of how we come to believe very basic conditionals and generalizations is unimportant or uninteresting; the point is simply that the PWB architecture sheds no light on the matter.

\subsection{Some objections considered}

Before moving on to explain how the SA account explains the phenomena grouped under the rubric of inference, I will consider a few responses to the "needless or useless" argument just levied against DCA views.

\subsubsection{Belief-distinct commitments?}

First, one might grant that while the PWB itself contains only the copied contents of the Belief Box, tokening a representation in the PWB could very well allow other kinds of cognitive faculties (e.g., innate modules, tacitly acquired processes) that underlie additional commitments (in a broad sense of "commitment") to be brought to bear in the generation of further inferences within the PWB, so long as there were the right connections between those faculties and the PWB. In response, we can grant that there may be cognitive resources in addition to one's beliefs that are brought to bear in determining what would happen if $p$. The question at hand, however, is whether the PWB itself supplements what can already be accomplished by the Belief Box, provided that the Belief Box has access to these additional cognitive resources as well.

\footnotetext{
${ }^{15}$ The DCA theorist may still press his point by noting that are some general facts that can only be appreciated through first considering particular cases, as when a philosophical thought experiment describing a particular situation is used to influence belief in a new generalization. Does this not show that something akin to a PWB is needed for at least some hypothetical reasoning tasks? This objection misses the point of the challenge being raised. The SA account does not deny that we sometimes come to infer a new generalization $g$ by thinking about a particular situation $p$. It simply insists that such an inference will only occur if one already has beliefs in generalizations relevant to determining what would happen if $p$, and that one does not need to represent that $p$ in order to make use of them in inferring the new generalization.
} 
Since there is no obvious reason to think that whatever connections might exist between the PWB and other cognitive faculties wouldn't equally well hold between the Belief Box and those faculties, there is no reason to think that the PWB itself would add anything to the reasoning processes in question, and hence no reason to find it explanatorily relevant.

\subsubsection{Does the PWB focus attention?}

A more promising objection might be that tokening in the PWB provides the necessary means by which cognitive attention is focused on the proposition $p$, whenever one pretends that $p$. By contrast, one might think that an intention or desire to determine what would happen if $p$ may not in itself be sufficient for causing the needed focus. As a reviewer notes, one could perhaps have scattered bits of information stored that are relevant to determining, say, the ethical consequences of a high carbon footprint lifestyle, together with an intention to determine these consequences, yet still fail to draw any conclusions because one never acts on the intention and carries out the relevant reasoning.

In response, while it is tempting to think of the PWB as an attention-focusing device, such a role does not fit with the way it is described by N\&S. For recall that, whenever a "pretend" proposition is tokened in the PWB, so are the entire contents of one's Belief Box (minus what is weeded out by the UpDater). One obviously does not then come to focus upon all of these propositions. So, the tokening of a proposition $p$ in the PWB is not by itself sufficient for allowing cognitive focus upon $p$.

But suppose that N\&S can somehow amend their account so that it does not require the entire contents of one's Belief Box to be copied into the PWB when a pretense begins. Would it then be plausible to hold that the PWB plays a crucial attention-focusing role? No, for the question of how attention is focused on a particular question and reasoning subsequently carried out is entirely general, extending well beyond the consideration of hypothetical statements, and thus beyond what the PWB could hope to explain. Suppose you are asked who among the high school classmates you've lost touch with is most likely now a lawyer. Answering requires you to focus your cognitive powers upon the question: "who of my classmates is most likely now a lawyer?" This focus allows you to retrieve relevant episodic memories, to weigh the values and relevance of a variety of personality traits against each other, and to draw new inferences. By what mechanism is this focus accomplished, assuming (for the sake of argument) that an 
intention to determine who is now a lawyer is not sufficient? I don't have a novel answer. ${ }^{16}$ The point is that whatever (non-PWB) mechanism enables attention to be focused on nonhypothetical questions and reasoning tasks will plausibly be the same mechanism that allows focus on questions of the form: what would happen if $p$ ? The SA account is free to avail itself of this general attention-focusing mechanism since it must be in place independent of the debate concerning the PWB. Moreover, it looks as if N\&S need to avail themselves of such mechanism as well to explain how only some of the many propositions in the PWB become objects of cognitive attention.

\subsubsection{Complexity concerns}

A last worry one might have is that if successful pretending requires keeping in mind what has already gone on in the pretense, the kinds of conditionals the SA account appeals to will quickly get much too large to handle-their antecedents much too long. Going back to the tea party, when the child has to make continuing inferences about what is true in the pretense, will she not have to infer a conditional that places almost everything that has gone on so far in its antecedent-e.g., "If you had poured tea into both cups, and overturned them, and asked me which was empty, and put a cookie on the plate, and noted the delightful weather, and complemented Teddy's outfit, and etc., etc., then...."?

The short response here is that we must not confuse the particular conditionals inferred during a pretense with the total information stored about the pretense (and which can be drawn upon in inferring those conditionals). Given that distinction, there is no reason to think that the particular counterfactuals inferred during a pretense must contain in their antecedents all (or even much of) the information stored about the pretense. After all, inference in general does not require believing conditionals with all of one's standing beliefs as parts of the antecedent, even if there is a rational norm according to which one's inferences ought to be consistent with all of one's standing beliefs. Similarly with pretense, there is a norm according to which one's pretense-guiding inferences should be consistent with what one knows about the pretense, but this does not require that the antecedents of the conditionals that drive the pretend behavior

\footnotetext{
${ }^{16}$ Perhaps the intention to determine who was the best leader causes the question "who was the best leader?" to be broadcast to a "global workspace" (Baars 1988, 1997, 2002), whereby connections are made available to a variety of other cognitive resources. Or, in lieu of a global workspace, we might suppose that the question is tokened in working memory (Baddeley 2007), which thereby allows the needed cross-talk among cognitive faculties.
} 
contain all of the information one has stored (in the Belief Box) about the pretense. It simply requires that one not overlook relevant facts about the pretense when making the inferences.

So, when the experimenter takes the green cup and turns it upside down, shaking it, the child appropriately updates her beliefs by accessing only relevant stored information, in particular: we are acting as if the cups are full. She then infers: "If the cups were full and you overturned the green one, the green one would be empty," which enables her to give the answer. The trick, of course, is not to forget some relevant information about the pretense in inferring the conditional (e.g. "we are acting as if there are lids on the cups"). Accomplishing this "trick" is not a trivial cognitive feat. ${ }^{17}$ But the difficulty lies entirely in remembering what has happened in the pretense-in what ways have we been acting as-if as part of the current pretense game? ${ }^{18}$ The same trick must be accomplished in ordinary inference as well. When told that Bob is at the airport, it will be reasonable to infer that he is travelling today-unless we also believe that Bob works at the airport, in which case we'd better not forget that when drawing an inference from his being at the airport.

\subsection{Explaining inference - mirroring and diverging}

I return now to explaining the pretense phenomena grouped under the rubric of 'inference.' A first question was what accounts for the "inferential orderliness" of the various inferences made during pretend play—why is it that what we infer of pretend scenarios so closely mirrors what we would infer if we believed the pretend premises? N\&S account for this by positing that the same inference mechanism works on representations in the PWB as in the Belief Box - an identity of mechanism enabled by the representations in each box being "in the same code." On the SA view, the answer is simpler: the beliefs concerning conditionals and generalizations that guide inferences and behavior in a pretense are generally the very ones that guide the corresponding inferences and behavior in real life. For example, if one is told, "pretend that Bob was in New York on Monday, and London on Tuesday," one will typically infer, as part of the pretense, that Bob got to London via airplane, just as one would infer that he'd gone by airplane if one came to believe through testimony that Bob was in New York on

\footnotetext{
${ }^{17}$ Depending on the cognitive age and emotional investment of the pretender, we will have varying expectations about how much of what is true "only in the pretense" must be appropriately taken into account in their responses going forward (we are not disappointed if a three year old pretender's behavior contradicts or ignores some of what has already gone on in a pretense as it develops, while the lapse is less forgivable in, say, an improvisational comedy act).

${ }^{18}$ See Section 5 for more details on how parts of the "pretense game" are distinguished from non-pretense.
} 
Monday and London on Tuesday. This "mirroring" is due to the fact that we tend to fill out pretend and actual scenarios by appeal to the same beliefs about how things normally go; in this case, the relevant belief is that people who travel that far that fast usually do so by airplane.

Why do we do it this way? Why does imagining that $p$ feed off beliefs concerning what would be likely if $p$ ? Here I think we have a pseudo-question; imagining that $p$, on the SA view, just is bringing to mind beliefs concerning what would likely happen if $p$, usually by drawing inferences from other beliefs deemed relevant. The question of why the inferences drawn "in imagination" mirror those that would be drawn from "isomorphic" beliefs is puzzling only if one begins with the view that imagining is not itself a way of believing, and that the propositions involved in imagining are quarantined in their own special "box." Only then will it seem attractive to attribute the "mirroring" to a mechanism that treats the representations in both boxes in roughly the same way.

Of course, imagining that $p$ and pretending that $p$ tolerate a good deal of divergence from our beliefs about what would likely happen if $p$, and from what our actual behavior would be if p. It might be thought that the creativity of imagination-our ability to imagine things we would never anticipate actually occurring-poses a problem for the present account. However, creativity poses no particular problem. The creative freedom of imagination-and the resultant freedom of pretense-derives from our ability to insert a new premise into our imaginative projects whenever we wish, and to draw out further inferences from it. Here "inserting a new premise" $n$ to an imaginative project that $p$ amounts to asking oneself what would likely happen if $n$ and $p$.

We need posit no special process or cognitive mechanism by which new and unusual premises are occasionally selected and used to extend an imaginative project (no "Script Elaborator" of the kind N\&S propose). The processing is simply driven by one's desires and interests with regard to the pretense or imagining. If you wish to pretend that a tornado strikes at the tea party, you use stored generalizations about tornados to reason about how they would affect a tea party. The freedom of imagination is just a special case of the more general freedom we have to reason about topics of our own choosing. Sometimes this involves reasoning about the likely consequences of scenarios that are themselves deemed unlikely or unusual. We need not (should not) conceive of the freedom of imagination as a freedom to represent or otherwise "entertain" propositions we hold to be false. ${ }^{19}$

\footnotetext{
${ }^{19} \mathrm{My}$ (forthcoming) develops further the same idea with respect to sensory or "perceptual" imagination.
} 
This concludes my argument against DCA theories of pretense and imagination. The SA account is an important alternative to have on the table, as its viability suggests that the core posit of DCA theories - the distinct cognitive attitude itself-is either needless or useless. In order for the SA account to stand on its own as an adequate theory of pretense, however, it needs to be situated in relation to another prominent account of pretense, the "metarepresentational" theory of Leslie $(1987,1994)$ and Leslie and colleagues (Friedman and Leslie 2007; Friedman et al. 2010).

\section{Recognizing pretense in others}

Leslie (1987, 1994) and Leslie \& Friedman's (2007) account of pretense shares similarities with N\&S's in its focus on the importance of "quarantining," though recently Friedman \& Leslie (2007) (hereafter "F\&L") have raised two powerful objections to N\&S's account of pretense recognition that their own does not seem to face. The first is that N\&S's account wrongly predicts that children will readily mistake much non-pretend behavior as pretense (in this way it is too broad); the second is that it is ill-equipped to explain certain specific kinds of pretense, such as object substitution and sound effects pretense (in this way it is too narrow). If cogent, these objections would apply equally to the SA view as I have so far developed it. I respond to the objections in this section, elaborating somewhat the SA theory in the process.

Let us turn first to the "overly broad" objection concerning pretense recognition. Friedman \& Leslie label N\&S's account of pretense recognition "behavioral" because it suggests pretense can be recognized in others solely through the detection of certain outward behavioral cues, without one's needing to attribute any mental states to the observed pretender. According to $\mathrm{N} \& \mathrm{~S}$, children are able to recognize that someone is pretending that $p$ simply by recognizing that "the other person is behaving in a way that would be appropriate if $p$ were the case" (Nichols \& Stich, 2000, p. 139, emphasis in original). To understand that Mommy is pretending that the banana is a telephone, the child need only discern that Mommy is "behaving in a way that would be appropriate if the banana were a telephone" (ibid.). Recognizing that someone's behavior is of the kind that would be appropriate if $p$ does not require attributing to that person any mental states - it does not require "metarepresentation" in Leslie's $(1987,1994)$ sense. This is an attractive position if one is skeptical that two year olds (who, as earlier remarked, are 
skilled recognizers of pretense but have trouble passing standard false-belief tasks) can accurately attribute mental states to others. Further, it is consistent with Lillard's $(1993,2001)$ finding that even four and five year old pretenders lack a proper understanding of the relation between an agent's knowledge and intentions on the one hand, and what she possibly pretend on the other (see fn. 7). For these reasons, behavioral accounts of pretense recognition have found wide support (P.L. Harris 1994; Jarrold et al. 1994; Lillard 1994; Nichols and Stich 2000; Perner 1991).

However, F\&L plausibly argue that this cannot be all that goes into recognizing pretense, in the process casting doubt on all existing behavioral accounts. First, it fails to distinguish cases of acting in error as if $p$ (because one falsely believes that $p$ ) from pretending that $p$, as both involve acting as would be appropriate if $p$. When Mommy swats a bread crumb because she thinks it is a fly, the behavioral account wrongly predicts that she will be interpreted as pretending to swat a fly. Second, the behavioral account predicts that children will over-interpret people as pretending that $p$ whenever they happen to note a similarity between the person's actions and the actions that would be appropriate if $p$. That is, people who act as if $p$ without intending to will nevertheless be interpreted as pretending that $p$. For instance, in writing with a piece of chalk someone is also acting (more or less) as would be appropriate if he were writing with a pencil, and so should be interpreted as pretending to write with a pencil. ${ }^{20}$

Finally, one typically acts as would be appropriate if $p$ when one correctly believes that $p$ and is in no way trying to pretend. For example, one normally acts as would be appropriate if one were driving a car when correctly believing oneself to be driving a car. If recognizing that someone is pretending that $p$ were just a matter of recognizing that he is acting as would be appropriate if $p$, almost any sincere act would potentially be confused for an act of pretense. Behavioral theorists cannot avoid this last problem by simply adding that the child must also recognize that not-p, since, as we've seen, it is possible to pretend that $p$ while $p$ is the case (recall the case of pretending that the empty cup is empty).

Friedman and Leslie conclude that pretense recognition cannot proceed through detection of particular behavioral patterns alone, and that it requires in addition competence with the (primitive, and perhaps innate) concept PRETEND, where this is a concept of a kind of mental

\footnotetext{
${ }^{20}$ Lillard (1993) showed that children do sometimes make this kind of error. However, F\&L might reply that pervasive confusions of this kind do not occur, despite the fact that one's actions are almost always appropriate to some other kind of action than what one intends.
} 
state (2007, pp. 107-109). A child recognizes that Mother is pretending the banana is a telephone not by noting that she is acting as would be appropriate if the banana were a telephone, but rather by making a judgment of the form: "Mother pretends (of) this banana (that) 'it is a telephone"” (2007, p. 108; Leslie \& Frith, 1990). It remains an open (and not trivial) question by which behavioral cues the child is able to correctly apply the concept PRETEND. Here F\&L appeal to manner cues such as exaggerated movements, unusual vocal intonation, and "knowing looks and smiles" (2007, pp. 120-121). They argue that, combined with possession of the concept PRETEND, familiarity with a certain cluster of manner cues suffices to circumvent the problems faced by N\&S's (and, by extension, my) behavioral account.

However, to preserve a purely behavioral account of pretense recognition, one can appeal to the detection of same manner cues (the winks-and-nods, unusual tone of voice, exaggerated gestures, stopping actions short of normal goal points, and so on) to which F\&L appeal, together with detection of some behavior that would be appropriate if $p$. That is, in determining that someone is pretending that $p$, the child may look for two things together: some of a particular cluster of manner cues, and some behavior that would be appropriate if $p$. Through experience and positive reinforcement, the child learns that when these conditions are met, the right thing to do is to follow along with the adult in acting in ways that would be appropriate if $p$, even if (as is usually the case when such cues are detected) $p$ is obviously not the case. These are the rules of the game, and they can be learned in the same way the child learns the rules to any game that does not require the representation of another's mental states. The manner cues are also used to focus attention on the aspect of behavior that constitutes pretense. ${ }^{21}$

Whereas F\&L think such cues and heuristics enable the child who possesses PRETEND to infer that the parent takes the mental "attitude" of pretense toward the proposition that $p$, "behaviorists" can hold that the cues allow the child to recognize the context as one where they should join in acting in ways that would be appropriate if $p$, whether or not $p$ is really the case. Since these manner cues are not present in the three kinds of "overly broad" problem cases F\&L raise for behavioral accounts, and since, by hypothesis, children will only infer that another is pretending in the presence of such cues, F\&L's criticism falls short.

\footnotetext{
${ }^{21}$ For instance, in giving an exaggerated yawn and saying loudly, "Oh, I'm so sleepy!" the adult cues the child that it is sleep-appropriate behavior that constitutes the pretense, and not English-speaker appropriate behavior (it is the exaggerated nature of the gesture and intonation that is a typical manner cue).
} 
However, F\&L are well aware that behavioral theorists would like to appeal to manner cues for help. They argue that behavioral theories cannot appeal to such cues because the very cues that enable one to reliably distinguish episodes of pretending that $p$ (the winks, the nods, the exaggerated expressions, the stopping short completing an action) will not themselves be behaviors that would be appropriate if $p$ (2007, p. 112). In their view, this clashes with the behavioral theorist's claim that recognizing a pretense that $p$ involves recognizing that someone is acting as would be appropriate if $p$.

But the behavioral theory has ample room to maneuver here. Once the account is amended to include the detection of manner cues together with some behavior that would be appropriate if $p$, the fact that some of the manner cues will involve acting in ways that would not be appropriate if $p$ poses no problem. For to act as would be appropriate if $p$ in the behaviorist's sense does not require that one act exactly as would be appropriate if $p$, but rather that one act in some salient respects as would be appropriate if $p .^{22}$ Suppose we are pretending that containers of mud are chocolate cakes. We can agree with F\&L that the knowing looks and the stoppingshort-of-eating are not behaviors that would be appropriate to engage in with chocolate cake. Yet, in concert with some salient behavior that would be appropriate to engage in with chocolate cakes (e.g., cutting them up, saying "Mmm, I love chocolate cake"), the manner cues enable the child to recognize the context as one where she should also act in ways that would be appropriate if the mud containers were chocolate cakes. To summarize this behavioral heuristic:

Behavioral heuristic: a person can be reliably recognized as pretending that $p$ by recognizing that she is acting in some salient ways that would be appropriate if $p$, while offering some of a familiar cluster of manner cues, some of which involve acting as if not-p and draw attention to the subject matter of the pretense.

Friedman and Leslie might nevertheless press their case by arguing we have secretly attributed the child the concept PRETEND in giving the child the ability to "look for" combinations of specific manner cues together with instances of acting in ways that would be appropriate if $p$ (as they emphasize, "one must guard against secretly interpreting act-as-if as actas-if pretending" (p. 119)). In one sense, we certainly have ascribed the child the concept PRETEND, to the extent that being able to detect and play such games constitutes understanding

${ }^{22}$ Compare: we easily recognize the actor playing Hamlet as behaving in ways that would be appropriate if he were Hamlet, while recognizing that he is also behaving in ways that would not be appropriate if he were Hamlet (e.g., ignoring the 500 people watching him from the theater). Recognizing the two together enables us to recognize that he is merely pretending to be Hamlet. There is no difficulty in the matter. 
pretense. In this (behavioral) sense of 'pretend', the child fully understands that the parent is pretending - and indeed that the parent is acting as if pretending. The important point is that we have not thereby given the child the concept of a mental state. Rather, we have given the child the concept of a kind of game, the recognition and playing of which does not require an understanding of mental states. Only by begging the question in favor of their account can F\&L hold that understanding someone is acting as if pretending necessarily involves understanding that person to have certain mental states.

Note also that to provide a behavioral criterion for reliable pretense recognition is not to give a behavioral account of what it is to pretend; it is not to suggest that necessary and sufficient criteria for pretense can be given without mentioning any mental states. Rather, like a disease, pretense can be reliably recognized by its outward symptoms, even if elements of its "essence" are not thereby grasped.

The second shortcoming F\&L detect in N\&S's account of pretense as "acting as would be appropriate if $p$ " is that there are many cases of pretending that $p$ that (manner cues aside) do not involve one's behaving as would be appropriate if $p$. This is the "too narrow" criticism mentioned above. Consider a case of pretending that a pencil is a car (what F\&L call "object substitution"), where the pretender pushes the pencil along the table ("substitution motion") and makes Vroom noises ("sound effects pretense"). In pushing the pencil along a table and making Vroom noises, the pretender does not behave as would be appropriate if the pencil were a car. For, if the pencil were a car, it would not be appropriate for the pretender to be pushing it or making Vroom noises! The pencil/car would be doing those things itself.

This objection mirrors the one above, where it was noted that the manner cues that serve to tip one off that someone is pretending that $p$ are not themselves behavior that would be appropriate if $p$. Once the general matter of pretense recognition is resolved (as above), these examples do not pose a deep problem for behavioral accounts of pretense. They simply require some delicacy in how the purely behavioral aspect of pretense is specified. While there is no reason to expect a single characterization to apply to all instances of pretense, a more general description of the behavioral aspect of pretending that $p$ than "acting in ways that would be appropriate if $p$ " is available. To see how, first note that very many instances of "pretending that p' (and, in particular, the ones raised by $\mathrm{F} \& \mathrm{~L}$ as challenges to behavioral accounts) can be understood as instances of 'pretending that $x$ is $y$,' so long as we allow that $x$ and $y$ can stand for 
a variety of things, including objects, actions, and situations. For example, if you pretend that the pencil is a car (where $p=$ 'the pencil is a car'), the pencil is $x$ and a car is $y$. If I pretend that I am a dolphin, I am $x$ and a dolphin is $y$. When you pretend that you are at a tea party, you are $x$ and 'at a tea party' is $y$. Given this way of expanding $p$, we can then say that part of the behavior involved in pretending that $p$ involves making $x$ saliently $y$-like (here I assume, as noted above, that all pretense involves outward behavior-mere imagining is not pretending). Pretense behavior is therefore driven (partly) by a desire or intention to make $x$ have some salient properties of $y$ s; or, where $y$ is a kind of situation or action, salient properties of things in those kinds of situation or undergoing those kinds of actions. Note also that part of making $x$ saliently $y$-like (when you yourself are not $x$ ) can involve making your reactions to $x$ of the kind you would have toward $y$.

So, in the case of pretending that the pencil is a car, the father tries to make the pencil saliently car-like; in the case of my pretending to be a dolphin, I try to make myself saliently dolphin-like; in pretending to be at a tea party, you try to make yourself act in some salient at-atea-party-like ways. Turning to the matter of pretense recognition, in recognizing the pencil/car pretense, the child recognizes that the father is trying to make the pencil saliently car-like (as above, manner cues both direct her attention to the pencil, and allow her to recognize that he is starting a pretense game with respect to the pencil). One way to make the pencil car-like is to cause it to move forward and backward around the table, since a salient feature of cars is that they move forward and backward. Of course, it is not a salient feature of cars that they have hands moving them, but the hand's involvement is necessary to bring about some other salient resemblance. Another salient feature of cars is that their motions are accompanied by Vroom sounds. In making Vroom sounds while the pencil moves around the table, the father makes the pencil car-like in the respect that its movements are accompanied by Vroom sounds. Of course, the Vroom sounds of cars are made by engines, not mouths. Perfect resemblance is not achieved—but, fortunately, pretense does not require it. The point of pretense is to go some distance toward making some $x$ saliently $y$-like. ${ }^{23}$

\footnotetext{
${ }^{23}$ Friedman et al. (2010) conducted an experiment where it was pretended that a teddy bear was talking (the experimenter spoke for the bear in a distinctive tone of voice, moving the bear in rhythm with the speech (p. 316). They argue that behavioral accounts cannot explain how children understand such pretenses. Put into the above formula, "teddy bear" is $x$ and "talking creature" is $y$. The child recognizes the pretense by recognizing that the experimenter is making the teddy bear act saliently talking-creature-like. Of course, the experimenter is doing the speaking, not the teddy bear. But, as noted above, salient resemblances are cheap: the teddy bear is still being made to behave like it is a talking creature to the extent that words are audible when talking creatures use their movements
} 
Friedman and Leslie anticipate a response similar to the one just offered, where the behavioral description of pretense is modified in particular ways (pp. 116-118). To counter it, they fall back on the "too broad" argument that, even if we accept such accounts of the kinds of behavior that constitute object-substitution pretense and sound-effect pretense, children should still mistake much non-pretend behavior for pretense. For instance, when the parent tosses a ball, the child should at times misinterpret the parent as pretending that the ball is an airplane, because the ball has been made to have some salient properties of airplanes (flying as it is through the air). But here the same response previously given is available. In line with the behavioral heuristic (now slightly modified), one can hold that the detection of manner cues together with detecting that $x$ has been made saliently $y$-like is what the child uses to discriminate cases of pretending that $x$ is $y$ from cases of merely making $x$ saliently $y$-like. Formally: recognizing that someone is pretending that $x$ is $y$ can be accomplished by recognizing that one is making $x$ saliently $y$-like while engaging in some of a familiar cluster of manner cues, some of which focus attention on the subject matter of the pretense.

I conclude that F\&L's criticisms of behavioral accounts fall short. Recognizing pretense does not require possession of mental state concepts.

\section{Conclusion}

Most current researchers are convinced that pretense requires a DCA and correspondingly distinct elements of cognitive architecture. Those who disagree typically hold that pretense requires possession of "metarepresentational" mental state concepts. I have argued that neither view is inevitable: pretense requires neither a DCA nor possession of mental state concepts. Moreover, DCA views seem to require the irrelevance of their core posit (the "PWB"). As noted at the outset, there are phenomena outside of pretense that DCA theorists adduce in favor of positing a DCA. I must leave discussion of those for another day. My hope for now is only to have loosened somewhat the grip DCA theories have had on imagination.

to demand one's attention and are similarly audible as the child's attention is focused on the bear. Attention is focused through the experimenter's use of the unusual (low) tone of voice in rhythm with the bear's movements, where these movements are exaggerated versions of the movements that normally accompany a talking creature's speech; these manner cues indicate to the child that a pretense game is occurring (as described above) that is focused on the bear, enabling the child to interpret the low voice as an instance of making the bear saliently talking-creaturelike (and not the experimenter!). 
Acknowledgements: Many thanks to an anonymous reviewer for this journal for several helpful criticisms and organizational suggestions. This work also benefitted from discussions with Jonathan Adler, Michael Levin, John Greenwood, José Luis Bermúdez, Josh Knobe, Jacob Beck, David Michael Kaplan, and Roy Sorenson. Thanks also to the audience at Washington University in St. Louis where a version of this paper was presented. Last but not least, thanks to Shaun Nichols and Stephen Stich for their groundbreaking work on this subject. 


\section{References}

Baars, B. (1988). A Cognitive Theory of Consciousness. Cambridge: Cambridge University Press.

Baars, B. (1997). In the Theatre of Consciousness. Oxford: Oxford University Press.

Baars, B. (2002). The conscious access hypothesis: origins and recent evidence. TRENDS in Cognitive Sciences, 6, 47-52.

Baddeley, A. D. (2007). Working memory, thought and action. Oxford University Press.

Bloom, P., \& German, T. P. (2000). Two reasons to abandon the false belief task as a test of theory of mind. Cognition, 77(1), B25-B31.

Bosco, F. M., Friedman, O., \& Leslie, A. (2006). Recognition of pretend and real actions in play by 1- and 2-year-olds: Early success and why they fail. Cognitive Development, 21, 3-10.

Buttlemann, D., Carpenter, M., \& Tomasello, M. (2009). Eighteen-month-old infants show false belief understanding in an active helping paradigm. Cognition, 112, 337-342.

Carruthers, P. (2006). Why Pretend? In S. Nichols (Ed.), The Architecture of Imagination. Oxford: Oxford University Press.

Currie, G., \& Ravenscroft, I. (2002). Recreative Minds: Imagination in Philosophy and Psychology. Oxford: Clarendon Press.

Doggett, T., \& Egan, A. (2007). Wanting Things You Don't Want: the Case for an Imaginative Analogue of Desire. Philosophers' Imprint, 7(9), 1-17.

Friedman, O., \& Leslie, A. (2007). The conceptual underpinnings of pretense: Pretending is not 'behaving-as-if'. Cognition, 105, 103-124.

Friedman, O., Neary, K. R., Burnstein, C. L., \& Leslie, A. (2010). Is young children's recognition of pretense metarepresentational or merely behavioral? Evidence from 2and 3-year-olds' understanding of pretend sounds and speech. Cognition, 115, 314-319.

Gendler, T. (2003). On the Relation Between Pretense and Belief. In M. Kieran (Ed.), Imagination, Philosophy, and the Arts. London: Routledge.

Gendler, T. (2006). Imaginative Contagion. Metaphilosophy, 37(2), 183-203.

Harris, P., \& Kavanaugh, R. D. (1993). Young children's understanding of pretense. Monographs of the Society for Research in Child Development, 58(1).

Harris, P. L. (1994). Understanding pretense. In C. Lewis, \& P. Mitchell (Eds.), Children's early understanding of mind: Origins and development (pp. 235-259). Hove: Lawrence Erlbaum Associates.

Harris, P. L. (2001). The Veridicality Assumption. Mind and Language, 16(3), 247-262.

Jarrold, C., Carruthers, P., Smith, P. K., \& Boucher, K. (1994). Pretend play: is it metarepresentational? Mind \& Language, 9(4), 445-468.

Langland-Hassan, P. (forthcoming). A Puzzle About Visualization. Phenomenology and the Cognitive Sciences.

Leslie, A. (1987). Pretense and representation: the origins of "theory of mind". Psychological Review, 94, 412-426.

Leslie, A. (1994). Pretending and believing: Issues in the theory of ToMM. Cognition, 50, 211238.

Lillard, A. (1993). Young Children's Conceptualization of Pretense: Action or Mental Representation State? Child Development, 64(2), 372-386. 
Lillard, A. (1994). Making sense of pretense. In C. Lewis, \& P. Mitchell (Eds.), Children's early understanding of mind: Origins and development (pp. 211-234). Hove: Lawrence Erlbaum Associates.

Lillard, A. (2001). Pretend play as Twin Earth. Developmental Review, 21, 495-531.

Nichols, S. (2004). Imagining and Believing: The Promise of a Single Code. Journal of Aesthetics and Art Criticism, 62, 129-139.

Nichols, S. (2006a). Introduction. In S. Nichols (Ed.), The Architecture of the Imagination (pp. 1-18). Oxford: Oxford University Press.

Nichols, S. (2006b). Just the Imagination: Why Imagining Doesn't Behave Like Believing. Mind and Language, 21, 459-474.

Nichols, S., \& Stich, S. (2000). A cognitive theory of pretense. Cognition, 74, 115-147.

Nichols, S., \& Stich, S. (2003). Mindreading. Oxford: Oxford University Press.

Onishi, K. H., \& Baillargeon, R. (2005). Do 15-Month-Old Infants Understand False Beliefs? Science, 308, 255-258.

Onishi, K. H., Baillargeon, R., \& Leslie, A. (2007). 15-month-old infants detect violoations in pretend scenarios. Acta Pscychologica, 124, 106-128.

Perner, J. (1991). Understanding the Representational Mind. Cambridge, MA: MIT Press.

Schroeder, T., \& Matheson, C. (2006). Imagination and Emotion. In S. Nichols (Ed.), The Architecture of the Imagination (pp. 19-40). Oxford: Oxford University Press.

Sobel, D. M., \& Lillard, A. (2002). Young children's understanding of pretense: Do words bend the truth? Developmental Science, 5, 87-97.

Weinberg, J., \& Meskin, A. (2006a). Imagine That! In M. Kieran (Ed.), Contemporary Debates in Aesthetics and the Philosophy of Art (pp. 222-235). Oxford: Blackwell.

Weinberg, J., \& Meskin, A. (2006b). Puzzling Over the Imagination: Philosophical Problems, Architectural Solutions. In S. Nichols (Ed.), The Architecture of Imagination (pp. 175204). Oxford: Oxford University Press.

Wellman, H. M., Cross, D., \& Watson, J. K. (2001). A meta-analysis of theory of mind: The truth about false belief. Child Development, 72, 655-684. 